\title{
Práticas culturais educativas na constituição do cenário musical no Brasil: as partituras em revistas ${ }^{1}$
}

\author{
Mônica Yumi Jinzenji \\ Eliane Marta S. Teixeira Lopes** \\ Paulo Henrique P. C. R. Alves ${ }^{* * *}$
}

\begin{abstract}
Resumo
O objetivo deste artigo é analisar a publicação e circulação de partituras em A Revista da Semana como prática educativa que constitui o cenário musical brasileiro no início do século XX. Para isso, propomos o aprofundamento da noção de educação e adotamos o conceito de práticas culturais educativas, nos referindo ao papel educativo dos impressos periódicos. Utilizamos como fontes principais 40 partituras que circularam no interior da Revista da Semana e que faziam parte da coleção de um pianista amador de Minas Gerais. Cotejando essas partituras, os estilos musicais contemplados e o contexto político e cultural do Rio de Janeiro, foi possível verificar a forte influência europeia e também norteamericana no desenvolvimento do repertório musical brasileiro naquele período. O consumo das músicas em revistas promoveu e fortaleceu hábitos, tais como bailes, saraus, transposições de peças escritas para piano para instrumentos de sopro e corda por músicos amadores e não leitores de partituras.

Palavras-chave: práticas educativas; história da educação; revistas literárias; história da música.
\end{abstract}

\section{Educational practices in the constitution of a music scene in Brazil: scores in magazines}

\begin{abstract}
\section{Introdução}

Este texto busca contribuir para aprofundar o entendimento sobre educação destacando a necessidade de ampliar seu significado. Trata-se de um tema/campo em sua essência interdisciplinar que demanda um tratamento interdisciplinar. É bastante comum pensarmos em "escola" como a principal referência ao se falar em educação. De fato, a escola hoje desfruta de um status privilegiado na formação das novas gerações, o que foi conquistado muitas vezes em disputa com outras instâncias, espaços e instrumentos que historicamente se constituíram nesse papel: a igreja, as famílias, o trabalho, a literatura, por exemplo.

Desenvolvemos este estudo a partir de dois pontos centrais: primeiramente, é necessário

*Endereço eletrônico: monicayj@ufmg.br

** Endereço eletrônico: emtlopes@uai.com.br

*** Endereço eletrônico: phpity84@yahoo.com.br
\end{abstract}

This paper aims to analyze the publication and circulation of music in the magazine A Revista da Semana as an educational practice which makes the Brazilian music scene in the early twentieth century. We propose a deepening of the concept of education and we adopt the concept of educational cultural practices, referring to the educational role of print journals. We use as main sources 40 scores that circulated within the magazine which were part of the collection of an amateur pianist of Minas Gerais. By comparing these scores to its musical styles and the political and cultural context of Rio de Janeiro, it was possible to verify the strong European and also U.S. influence in the development of the Brazilian musical repertoire in that period. The consumption of this musics from magazines promoted and strengthened behaviors, such as balls, soirees, transpositions of pieces written for piano to wind instruments and string by amateur musicians and non- readers of music.

Key-words: educational practices; history of education; literary magazines; the history of music.

compreender o processo de desenvolvimento histórico das diversas práticas educativas que preexistiam à escola moderna e que, mesmo após a consolidação desta, seguiram e seguem participando da formação e educação das novas gerações e da população como um todo; em seguida e por consequência, cabe operar um novo conceito que possibilite pensar a educação num sentido mais ampliado. O termo práticas culturais educativas parece sintetizar o objeto de estudo aqui trazido para análise: a circulação de partituras por meio de revistas literárias no início do século XX no Brasil e sua contribuição para a constituição de um cenário musical. Para isto, buscamos o diálogo interdisciplinar entre os campos da História da Educação, História da Cultura Escrita e da História da Música. 
A origem deste estudo está no acervo pessoal de um músico diletante, exímio intérprete de peças para piano e que era apresentado como "O Príncipe do Teclado" quando tocava na Rádio Mineira na primeira metade do século XX, em Belo Horizonte. Natural de Queluz de Minas (hoje Conselheiro Lafaiete-MG), DATL como iremos identificá-lo, lá viveu de 1910 a 1926, quando se mudou para a capital. Em Belo Horizonte, aos 18 anos abriu mão da carreira de pianista e pôde, assim, se dedicar a tocar o que mais lhe aprazia até próximo de seu falecimento, em 2007. Ao longo dos anos colecionou e "herdou" coleções de partituras que contabilizam mais de mil peças e estas se encontram hoje sob a guarda do Museu da Música de Mariana em Minas Gerais, onde estão sendo digitalizadas para disponibilização à consulta pela internet. Desse conjunto, as partituras que nos interessam são as que foram retiradas de revistas literárias brasileiras de ampla circulação: Revista da Semana (Rio de Janeiro, 1900-1959) e O Malho (Rio de Janeiro, 1902-1954). Esse corpus é formado por 121 partituras em que predominam músicas com forte influência europeia e norteamericana (algumas peças do repertório clássico e álbuns de estudo de piano), todas da primeira metade do século $\mathrm{XX}$. São, em sua maioria, compostas para piano e entre seus diversos compositores, alguns se tornaram nomes de destaque no cenário musical brasileiro. Para fins de delimitação desta pesquisa, serão analisadas as partituras extraídas d'A Revista da Semana.

Algumas questões surgem da problematização dessas fontes: nesse período em que ainda não existia o rádio, e o mercado fonográfico estava apenas iniciando suas atividades, a publicação de partituras em revistas seria um dos principais recursos para que o "público leitor" tivesse acesso às novidades musicais do momento. Nesse sentido, cabe perguntar: a quem se destinavam essas composições? Como eram executadas e em que circunstâncias? Qual o papel das partituras impressas em revistas na formação musical desse público? Como a recepção das partituras em revistas se organizava no conjunto de outras práticas culturais ou de outras formas de se fazer música no período? Numa população de maioria analfabeta, como seria o acesso ao conhecimento musical?

Essas perguntas visam compreender uma prática que envolve a transmissão de informações e conhecimentos e a sua recepção, resultando em transformações nos hábitos e repertório dos sujeitos envolvidos. Tal prática se desenvolve à margem das instâncias "formais" ou institucionalizadas de educação musical e, como desenvolveremos adiante, independem, em boa medida, do processo de alfabetização. Trata-se de considerar os sons do passado e seus significados no conjunto dos repertórios sociais e culturais daquele momento, na formação de um grupo social.

No campo da História da Educação, poucos são ainda os estudos que se desenvolvem em interface com a música ou sua história, a exemplo da tese de Flávio Oliveira (2004) que analisa a música como disciplina escolar no início do século XX e a tese de Maria Teresa Mendes de Castro (2012) que, ao estudar o desenvolvimento do ensino de piano em Belo Horizonte-MG, mescla as "paisagens sonoras" ao desenvolvimento social e urbano da cidade no início do século XX. Mais numerosos são os estudos que dão destaque às práticas educativas não escolares. A tese Colonizador-Colonizado: um movimento educativo no movimento da história (LOPES, 1985) abre a possibilidade dessa reflexão ao dar foco à prática política como maneira de educar. Nessa mesma direção, Carla Chamon (1999) analisa o caráter didático das festas cívicas escolares. Essa temática se adensa a partir de segunda década do século XXI, sendo apresentadas por algumas denominações recorrentes que indicam esses meios e espaços formativos: práticas educativas familiares (CARNEIRO, 2011; GORGULHO, 2011; SILVA, 2011), processos educativos envolvidos na aprendizagem de ofícios (FONSECA, 2006), teatro como estratégia educativa (Sá \& GALVÃO, 2011), o caráter formativo dos espaços de sociabilidade (JULIO, 2007; JINZENJI et al, 2012), as instâncias formativas não escolares (REIS, 2010; GALVÃO et al, 2013) e, por fim, o periódico como educador (PALLARES-BURKE, 1998; BASTOS, 2002; REMEDIOS, 2003; LUSTOSA, 2003; CARLOS \& VEIGA, 2005; JINZENJI, 2010).

\section{O impresso periódico como agente educativo e a circulação de partituras como prática cultural educativa}

Jornais e revistas são agentes da história e não simplesmente o registro dela. Tal concepção à qual a argumentação central deste estudo se alia, comporta vários sentidos específicos que permeiam a prática educativa: segundo Bastos (2002), o impresso periódico "procura engendrar uma mentalidade - uma certa maneira de ver - no seu 
destinatário, constituindo um público-leitor". A imprensa como "fazedor[a] de opinião", segundo Remedios (2003) possui, em sua vertente católica, o caráter doutrinário; Carlos e Veiga (2005) salientam a "especificidade das estratégias jornalísticas na formação da opinião pública". Para Lustosa (2003), no início do desenvolvimento da imprensa no Brasil, "o jornalista se confundia com o educador. Ele via como sua missão suprir a falta de escolas e de livros através dos seus escritos jornalísticos".

Esse caráter educativo subjaz à identidade do próprio veículo de informação que é, portanto, de formação e que atravessa o tempo. Situando a imprensa periódica do início do século XX, durante a Belle Époque, o Rio de Janeiro fervilhava transformações; recebia influência das grandes metrópoles europeias cujas novidades espalhavamse para todo o restante do país. Houve transformações significativas na oferta de "equipamentos culturais" à população e, especificamente relacionado ao cenário musical, este foi marcado pela criação e ampliação dos espaços institucionalizados de ensino da música, como o Instituto Nacional de Música e o Liceu de Artes e Ofícios (ambos em 1891), as bandas, além de movimentos próprios da cultura popular (ALVES, 2011). Com tantas mudanças e influências, as revistas literárias surgiram como um grande marco na imprensa nacional. Com um caráter educativo e "civilizador", exaltavam sempre o que havia de mais requintado: as novidades em moda, arquitetura, beleza, entre outras, vindas de grandes capitais, principalmente de Paris, eram estampadas como exemplos para os brasileiros. Não foi diferente com a música, já que nas partituras impressas nos periódicos, os estilos que imperavam eram as danças europeias. O número de músicos e compositores brasileiros, nessa época, era bastante expressivo, uma vez que tocar era a principal forma de se ter música nos diversos espaços de sociabilidade.

Periódicos como A Revista da Semana, $O$ Malho, Fon-Fon!, Tagarela, Almanach d' O TicoTico e A Ilustração Brasileira tornaram-se veículos difusores da música no Brasil, embora não tenham vindo à luz com essa especificidade. É importante salientar que o mercado editorial de música já se desenvolvia no Brasil desde o início do século XIX, sendo o Brasil o país que, nesse período, mais editou música na América Latina (LEME, 2004, p. 1-15). De acordo com Cláudio Frydman (2008), os periódicos passam a ter um papel muito importante na propagação da música em todos os estados uma vez que até então a circulação de partituras estava restrita só ao Rio de Janeiro e aos grandes centros urbanos como São Paulo, Porto Alegre e Salvador.

Para Lins (2010), “originadas de um projeto mais amplo, de cunho coletivo, as revistas são ponto de encontro de itinerários individuais, reunidos em torno de uma ideia comum. Funcionavam como um verdadeiro microcosmo, no interior do qual os intelectuais organizam suas redes de sociabilidade, difundem ideias e garantem o seu sustento" (LINS, 2010, p.44).

Assim, nessa perspectiva, nasceu a Revista da Semana - um semanário brasileiro editado no Rio de Janeiro. Em suas edições, colaboraram importantes intelectuais e artistas da época, como Amaro do Amaral, Raul Pederneiras, entre outros. Seu primeiro número saiu no dia 20 de maio de 1900 , um domingo. Medindo $38 \times 27 \mathrm{~cm}$, possuía 8 páginas, 3 colunas em cada página, muitas ilustrações (desenhos e caricaturas), fotografias instantâneas (assim nomeadas pela própria revista) e propagandas. O periódico pertencia ao Jornal do Brasil $^{2}$, um dos principais jornais do país naquela época e tinha como redator-chefe o Dr. Fernando Mendes de Almeida (1845-1921), senador do estado do Maranhão, jurista e jornalista, participou da fundação da Faculdade Livre de Ciências Jurídicas e Sociais do Rio de Janeiro, embrião da atual Faculdade Nacional de Direito da Universidade Federal do Rio de Janeiro e de outras instituições de ensino. Seu irmão, Cândido Mendes de Almeida Filho (1866-1939), atuou como Redator Gerente. Outras figuras também foram muito importantes para a longevidade da Revista, como por exemplo os exímios ilustradores Raul Pederneiras (18741953), Luis Peixoto (1889-1973) que aos 15 anos publicou seus primeiros desenhos na Revista e o cartunista Amaro do Amaral [s.d.]. Todos eles publicaram charges, caricaturas e desenhos nos exemplares semanais.

A Revista da Semana nasceu com o rótulo: "Edição semanal Illustrada do Jornal do Brasil". Mas o que vinha a ser uma revista ilustrada? De acordo com Cláudia de Oliveira et. al. (2010),

as revistas semanais ilustradas
estruturavam seus textos de forma
estratégica para que o público leitor
sentisse cumplicidade e envolvimento.
Provocam, brincam, interpelam, chamando
insistentemente à participação. Foi uma
novidade que se propagou e se impôs no
início da centuária passada e jogaram um


papel fundamental não apenas na difusão de hábitos, costumes, valores $e$ sociabilidades urbanas. Elas foram fundamentais para rotinizar o moderno $e$ habituar o público às novas exigências espaçotemporais (OLIVEIRA et. al., 2010, p.9).

Em contraposição aos livros, que evocam caráter mais permanente, o conteúdo da revista nunca expressa um pensamento de forma definitiva. A revista é marcada por uma escrita dinâmica e que não visava captar a atualidade imediata e sim, tornála objeto de reflexão. Atraía muitos adeptos, por ter uma leitura sempre atualizada e diversificada, já que era semanal.

Anunciado na Carta ao Leitor, escrita pelo Dr. Fernando Mendes e publicada na primeira página do primeiro exemplar da Revista, diz-se "Feita para o povo - desde as infimas ás mais altas camadas sociaes". Seu baixo custo o tornava acessível à grande massa: custava 300 réis (valor pouco expressivo para época) ${ }^{3}$ e até mesmo os analfabetos podiam se "deliciar" em suas páginas, pois eram extremamente ricas em ilustrações e charges com um grafismo brilhante e fotografias, então grande novidade tecnológica ${ }^{4}$. Sobre isso, Gisele Taboada da Silva et. al. (2004) apontam que

a fotografia foi um recurso tão importante na "Revista da Semana" que havia até mesmo seções em estúdio em que eram fotografadas simulações de crimes para ilustrar as reportagens a serem publicadas. Mas, as reportagens de rua também tomavam lugar em suas páginas (SILVA et al, 2004, p.3).

Desde os grandes eventos públicos como inaugurações das novas avenidas e edifícios, dos fatos políticos e religiosos que aconteciam nas cidades do interior do Rio de Janeiro e dos outros estados da federação até as mais simples passagens do cotidiano privado eram retratadas em suas páginas. A Revista da Semana trazia em suas edições reportagens de cunhos diversos, além de coluna social, comentários sobre moda, fotos e gravuras de exposições da época, seções com a programação teatral, as festas religiosas, fotografias dos mortos em acidentes ou assassinatos, jogos e brincadeiras para entretenimento das crianças, charges e, sobretudo, partituras; enfim, tudo o que pudesse interessar a população era ali publicado. À medida que os anos foram passando, o periódico semanal foi aumentando o número de páginas e de assuntos abordados como, por exemplo, encartes de esportes, humorísticos, atrações infantis, entre outros.

A crescente receptividade e visibilidade públicas exigiram que as revistas aprimorassem a sua arte de comunicação aproximando-se dos leitores. Textos literários compartilhavam espaço com as artes gráficas, incluindo-se caricaturas, charges, desenhos, jogos de adivinhas e publicidade. Por suas páginas, é possível perceber o surgimento de novas formas de linguagem e de expressão, dentre elas uma que se destaca são as propagandas publicitárias. Nessas propagandas, é muito comum se perceber a chamada "Literatura do Aconselhamento", as quais sugerem as mais diversas práticas como, formas de fazer, usar, proceder e também de se informar - um corpo de instruções que abrange desde os primeiros cuidados médicos e sugestões de tratamentos higiênicos às receitas culinárias e de beleza, passando por consultório sentimental, moda, estética, esporte, astrologia, economia doméstica e um panorama das modernas conquistas científico-metodológicas. $\mathrm{Na}$ publicidade, além dos remédios e medicamentos, o apelo aos produtos de beleza e estética são profusos: produtos para evitar a queda dos cabelos e assegurar a perda de peso ganham crescente ênfase. Além disso, a Revista da Semana utilizava também suas páginas para fazer propagandas dela mesma, oferecendo assinaturas e anúncios para comerciantes nos números seguintes.

Revista da Semana pertenceu ao Jornal do Brasil até o ano de 1915. Nesse ano, foi comprada pela "Companhia Editora Americana" e recebeu, para sua nova fase, maquinários modernos vindos dos Estados Unidos para sua impressão, com adoção de novas cores, uma vez que até esse período quase todas as suas edições foram em preto e branco. Quando em raríssimas páginas apareciam cores, essas eram o vermelho e o azul.

O periódico circulou até o ano de 1959, quando foi publicada sua última edição datada de 03 de janeiro, por motivo desconhecido. Nesta pesquisa, porém, focaremos as publicações da primeira década do séc. XX, que compreendem as edições desde o surgimento da Revista (20 de maio de 1900) até o último exemplar de 1910, uma vez que a partitura mais antiga da coleção de DATL data de 1903 e a mais recente é de 1909.

\section{As partituras de DATL}


As 40 partituras aqui analisadas foram organizados em quatro "cadernos", cada um contendo um número variado de partituras, com estilos diversos, de diferentes autores e de fontes de publicação. Também não seguem uma sequência cronológica, havendo partituras de anos diversos num mesmo caderno, o que nos faz crer que elas foram lidas e "frequentadas" de forma independente antes de serem organizadas dessa forma. Cada um desses conjuntos de partituras foram agrupados e costurados à mão e possuem cada qual uma capa com numerações: caderno 1, caderno 2 , caderno 3 e caderno 6. Dois cadernos da mesma coleção parecem ter se perdido.

As datas da coleção de DATL coincidem com a regularidade em que as partituras foram ganhando espaço na Revista da Semana. Mais tarde, no período em que foram desaparecendo, de forma sutil, das edições, a coleção também passou a ter um número bem menor delas.

Os impressos musicais vinham como parte integrante do conteúdo e não como um caderno à parte, o que indica que a circulação desse material passou a ser difundido no país, principalmente por meio das referidas revistas. A primeira partitura publicada pela Revista da Semana aparece na edição $\mathrm{n}^{\circ} 9$ do dia 15 de julho de 1900. Tratava-se da valsa intitulada "Tes Yeux..." de Abdon Milanez. Não poderia ser um compositor qualquer o escolhido a inaugurar a seção musical da revista. Abdon Milanez (1858-1927) foi uma figura reconhecida e muito respeitada na história da música brasileira. No livro "Panorama da Música Popular Brasileira na Belle Époque" de Ary Vasconcelos, Milanez tem a foto estampada na galeria entre os que ajudaram a construir o que mais tarde seria denominada a MPB (VASCONCELOS, 1977, p. 30). Embora não tivesse feito cursos regulares de música, era considerado um excelente compositor, criando operetas e obras para o teatro de revista. Essa não foi a única partitura assinada por ele e publicada na Revista; em 1903 ele é o compositor que mais vezes aparece no periódico e, além dele, outros compositores que futuramente viriam a integrar a galeria dos grandes nomes na música popular brasileira, publicaram suas obras na Revista da Semana. É o caso de Chiquinha Gonzaga (18471935) que aparece como compositora de uma das partituras da coleção - "Angelitude" - e hoje é considerada por muitos críticos como "a mãe" da MPB. Pedro Assis (1880-1950) também foi grande compositor e colaborador da Revista; foi professor de flauta no Instituto Nacional de Música do Rio de
Janeiro e, como era apreciador do choro, harmonizou muitas obras para piano e flauta. Outro músico que frequentemente aparecia com as suas composições era Júlio Reis (1870-1933) - recordista nas composições da coleção com 7 partituras e um dos que mais aparecem em toda a primeira década da Revista - estudou órgão desde criança, mas acabou seguindo para a carreira de funcionário público no senado federal. Compôs inúmeras obras, inclusive uma Ave Maria regida pelo famoso maestro Henrique Alves de Mesquita. Não podemos nos esquecer de Aurélio Cavalcante (1874-1915) que foi o "ídolo músico-dançante de toda uma geração". Suas valsas exerceram no Brasil domínio comparável às de Strauss no resto do mundo (Enciclopédia da Música Brasileira, 1998, p. 54). Suas músicas eram adotadas desde os salões mais requintados às mais simples camadas sociais. Foi o compositor mais cogitado da época, principalmente pelas revistas que publicavam partituras. À exceção desses compositores, que vieram a se destacar no cenário musical posteriormente, a maior parte que tiveram suas músicas editadas na Revista eram músicos amadores e desconhecidos.

Em relação aos instrumentos para os quais as partituras foram escritas, das 40 peças, 39 foram compostas exclusivamente para piano, com uma única exceção: "A Divina Berceuse" que é para piano e coro uníssono para vozes de crianças. O grande número de publicações para o referido instrumento nesse período pode ser explicado pela forte influência trazida da Europa. Possuir um piano em casa mostrava poder e status social. Maria Luiza Queiroz (1942) registrou, só entre os anos de 1865-1890, um número de 249 professores de música e de instrumentos musicais, principalmente de piano, no Rio de Janeiro. De acordo com o Almanak Laemmert de 1888, eram 44 os fabricantes, negociantes, alugadores, afinadores e consertadores de pianos, órgãos, harmônios e realejos na cidade, e eram sete os negociantes de música impressa e de outros instrumentos neste período. Havia, no Rio de Janeiro, 16 lojas que dependiam fortemente da venda de pianos para girarem seus lucros. A venda e a manutenção de pianos era um lucrativo negócio.

Quanto ao estilo das peças, 22 são valsas sendo que três têm algumas variações: valsa (grazioso (sic.)), valsa lenta e valsa andante maestoso -, 7 schottischs, 7 polkas (dessas, 2 são polka-mazurka e 1 polka-característica), 1 tango brasileiro, 1 gavota, 1 cake-walk e 1 andante, o que demonstra a variedade musical apreciada pelo 
público consumidor dessas partituras. Fica evidente a influência da música de origem europeia, em especial as danças, e o instrumento para o qual eram compostas sugere que as peças eram executadas em bailes ou eventos festivos nos salões ou casas de família.

Os compositores eram em sua maioria homens, 31 no total; as mulheres compuseram 5 músicas e, em 4 , não foi possível definir se eram compositores ou compositoras, uma vez que os nomes viam abreviados, como por exemplo B. Vianna.

Algumas partituras possuem "marcas de leitura". Por exemplo, em três delas aparecem um X na parte de cima, acompanhada do vocábulo "Feia", escrito a lápis. Essas marcas, que podem ter sido feitas pelo dono da coleção - ou por outro leitor/a-, indicam a efetiva leitura, mas indicam também que a prática de colecionar partituras se sobrepunha ao gosto pelas peças daquela coleção. Outro tipo de marca significativa é a colagem com fita adesiva para o reparo de rasgos, feito em sete partituras, o que indica o manuseio - leitura e execução da peça e o apreço por elas.

Apesar do sucesso do mercado editorial de música, a periodicidade das partituras não acompanhou a da Revista da Semana nos seus primeiros anos. Da primeira composição em julho de 1900 até fevereiro de 1903 foram publicadas apenas 8 partituras ( 4 schottisch, 2 valsas, 1 polca e 1 canto gregoriano natalino). Somente, a partir do ${ }^{\circ}$ 146, de 01/03/1903 é que as partituras passam a vir com regularidade todas as semanas. Este período coincide, também, com a primeira partitura de nossa coleção: " 1 o de Maio", uma valsa datada de 17/05/1903 e que foi impressa no número 157 dos periódicos.

De março de 1903 a junho de 1907, a publicação de partituras na Revista da Semana ocorreu de forma ininterrupta, porém a partir daí elas passaram a aparecer de forma cada vez mais esporádica. No segundo semestre de 1907, há apenas uma música nas páginas do periódico. Em 1908, apesar das propagandas da Revista informarem que cada número da mesma acompanhava uma composição musical, elas não passaram de 20 no ano inteiro. Da mesma forma, no ano seguinte, 1909, foram publicadas apenas $16 \mathrm{e}$ todas no segundo semestre. No ano de 1910 as partituras praticamente desaparecem da Revista da Semana. Nos anos 20 elas voltam, porém muito mais influenciadas pelos ritmos americanos como o fox-trot e o ragtime. No final dessa década cessam, de vez, as publicações de partituras na Revista da Semana.

Os dados apresentados anteriormente podem ser analisados na tabela e no gráfico apresentados a seguir:

\section{TABELA 1}

Partituras publicadas pela Revista da Semana na primeira década do século XX

$\begin{array}{cc}\text { Ano da Publicação } & \text { Quantidade de partituras publicadas } \\ 1900 & 03 \\ 1901 & 03 \\ 1902 & 02 \\ 1903 & 47 \\ 1904 & 52 \\ 1905 & 52 \\ 1906 & 52 \\ 1907 & 25 \\ 1908 & 20 \\ 1909 & 16 \\ 1910 & 07\end{array}$

Fonte: Coleção da Revista da Semana disponível na Biblioteca Nacional - RJ 


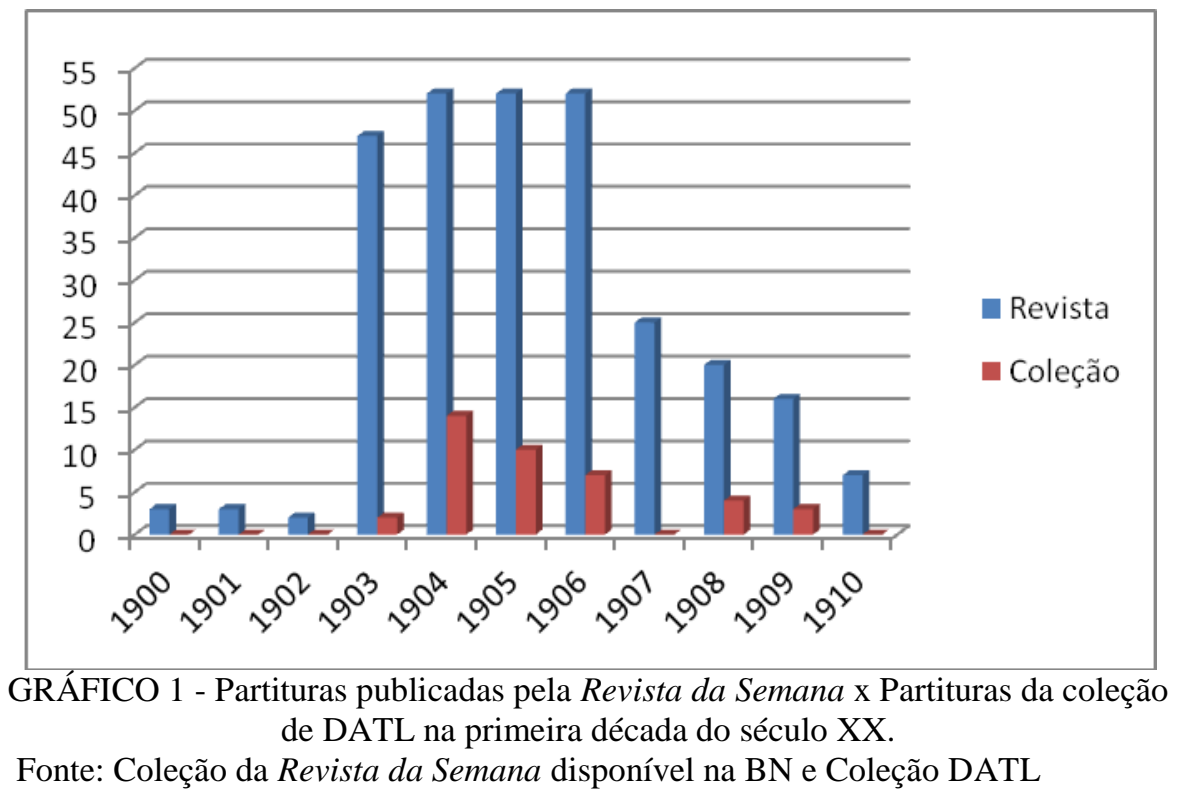

Com referência aos dados apresentados, Gabriel Rezende (2008) comenta que

o desaparecimento das partituras nas revistas literárias, talvez possa ser explicado pela popularização dos discos no Brasil e pela queda do preço do gramofone. A decadência da música impressa no Brasil também foi agravada com a chegada do rádio em 1923. Ambos passaram a ser objetos de desejo das famílias e, no lugar do piano, passaram a ser a alavanca de status. Era mais interessante ter um rádio ou um gramofone que um piano (REZENDE, 2008, p. 47).

Cláudio Frydman (2008) considera, ainda, que

com a crescente popularização do gramofone, existe um aumento da oferta de gravações nacionais e internacionais $e$ o Brasil se torna o terceiro maior produtor de discos do mundo. $O$ encanto com as máquinas é geral, e a burguesia carioca muda o paradigma da música executada por músicos ao vivo para música executada pelas mais novas tecnologias, isto é, passam da condição de ativos para passivos. Como já dizia Euclides da Cunha no clássico livro "Os Sertões", de 1902: "Estamos condenados à civilização. Ou progredimos, ou desaparecemos". A importância maior dada na imprensa à propaganda e também às fotografias, assim como a mudança de interesse por outras pautas, também diminui gradativamente a ocorrência e o espaço para a publicação de músicas, isto não só no Brasil como em outros países (FRYDMAN, 2008, p. 14).

\section{A implementação de novos hábitos culturais ou o cenário musical em construção}

Podemos dizer que a receptividade das partituras em revistas se tornou possível devido a um ambiente propício: embora houvesse grandes mudanças durante o Segundo Império, o Rio de Janeiro de fins do século XIX era ainda uma cidade provinciana onde era comum bailes nas casas de família e saraus domésticos. Com a família real portuguesa, chegaram também ao Brasil os primeiros pianos e o instrumento ganhou muitos adeptos na cidade. Em 1856, o escritor Araújo Porto Alegre já chamava o Rio de "Cidade dos Pianos" e a existência de tantos desses instrumentos foi sem dúvida de grande importância para a popularização da polca, a principal matriz entre as danças europeias e a mãe do nosso choro brasileiro. As diversões públicas, como cafés-dançantes dos remediados e os chamados chopes-berrantes dos mais pobres, só começariam a ploriferar nos últimos anos do século XIX e nos primeiros do XX (ALVES, 2011).

Em um tempo em que ainda não havia nem os discos nem o rádio, a única forma de se ouvir 
e/ou executar música era tocando. Segundo Laura Macedo (2009), era comum a presença de um piano nas casas dos mais abastados, ao redor do qual se realizavam reuniões familiares e saraus. Aprender a tocá-lo fazia parte da boa educação da época (MACEDO, 2009, [s.p.]; MAGALDI, 2004). Quanto às partituras, segundo Frydman (2008), as mulheres eram as principais consumidoras das páginas musicais.

na sociedade patriarcal eram incumbidas de cuidar dos filhos, das atribuições domésticas e de alegrar a casa tocando piano. Os homens também estudavam música. Possuir um piano e ainda por cima ser capaz de tocar, compor uma música e publicá-la na imprensa homenageando alguém era motivo de orgulho e status para a burguesia (e quem almejava pertencer a ela), ainda mais numa sociedade de maioria analfabeta $e$ sem poder político (FRYDMAN, 2008, [s.p.]).

Para o escritor José de Alencar (18291877), "o piano foi para a mulher o que o cigarro foi para o homem, um amigo para todas as horas e um fiel confidente". Entretanto, como vimos acima, saber tocar e compor também representava status para o homem. Resta saber se somente os homens e mulheres das camadas sociais mais privilegiadas frequentavam essas partituras. Teriam elas penetrado no repertório musical de outros estratos sociais da época?

A partitura foi criada com o objetivo principal de ser um veículo de comunicação, ou seja, um elo entre o compositor e o intérprete, além de ser um meio de transmissão dos conhecimentos musicais. É a representação escrita da "linguagem musical". Quem deteria a capacidade de decodificar seus significados? Ou, perguntando de outra forma, era necessário conseguir "ler" as partituras para se apropriar de seu significado sonoro? E ainda, havia conexão entre a leitura de partituras e a alfabetização?

Cabe lembrar que era grande a quantidade de analfabetos no Brasil. Em 1872, quando foi realizado o primeiro censo nacional, o índice dos que não sabiam ler e escrever era de cerca de $82 \%$ da população de cinco anos ou mais e, até os anos 60 do século XX, o índice de analfabetos permanece superior ao de alfabetizados: eles constituíam 82,3\% da população em 1890, 71,2\% em 1920, 61,1\% em 1940 e 57,1\% em 1950 (FERRARI, 1985 apud
GALVÃO, 2007, p. 11).

Segundo Reis (2001) as particularidades dos signos musicais não permitem relacionar diretamente alfabetização e leitura musical.

a partitura é um tipo de impresso que apresenta algum diferencial de outros impressos, possui particularidades em sua produção, circulação e uso. Formada por signos musicais, dentro de um código específico e próprio, a partitura é um texto que o intérprete deve ler, compreender $e$ transformar em um processo relacional de sons, na ordem estética dada pelo compositor no âmbito da forma (REIS, 2001, p. 496).

Sob o mesmo ponto de vista, Magnani (1996) acrescenta que

[...] é este o caso singular da música, em que a página escrita é uma supracifragem incompreensivel para quem não possua profundo conhecimento da linguagem $e$, irreal, mesmo para aquele que goze de uma desenvolvida capacidade de audição interna [...] (MAGNANI, 1996, p. 37).

Entretanto, não há também uma dependência "interna" da leitura musical ao processo de alfabetização. Ou seja, não era necessário saber ler para ser capaz de entender a escrita musical. Segundo Leme (2004),

há a possibilidade de ter havido trabalhadores escravos (analfabetos), porém qualificados, no processo de produção e difusão da música no Brasil, o que exigia precisão e habilidade artística. É possivel, inclusive, que alguns desses escravos tivessem conhecimento da escrita musical, recebendo lições para garantir a boa qualidade das partituras editadas. Por outro lado, os litógrafos que eram responsáveis por fazer as matrizes das partituras a serem copiadas, nem sempre possuíam esse conhecimento (LEME, 2004, p. 83).

Um exemplo interessante sobre as formas de letramento musical, que não são pelas partituras, aparece na própria Revista da Semana, no "Suplemento do João Paulino5". Nele eram comuns 
exercícios nos quais aparecia o desenho das teclas de um piano e uma sequência numérica acima delas. Seguindo-se a ordem dos números, era possível que a criança pudesse aprender uma melodia musical. Essa prática era comum e aparece em vários números do encarte infantil.

Fazendo uma análise das características musicais das partituras, Frydman afirma que "o público alvo das partituras era constituído por amadores, cujo nível técnico e pretensões musicais eram modestos, e a intenção principal deste repertório era proporcionar uma seleção de música de dança, por isso estas peças eram também muito rítmicas" (FRYDMAN, 2008, p.6).

Baseados nessas informações, podemos concluir que "neófitos" e mesmo as pessoas não alfabetizadas musicalmente podiam usufruir das partituras publicadas naquele periódico, pois participavam de alguma forma daquela música. Seja como ouvinte ou até mesmo tocando, como é o caso de muitos chorões ${ }^{6}$ que aprendiam as músicas escritas para piano "de ouvido" e transpunham as melodias e harmonias para os seus instrumentos (violão, flauta e cavaquinho).

a medida em que as partituras de polcas iam chegando e em alguns casos caindo no gosto dos pianistas que animavam as festas da classe média, os músicos populares passaram a copiar aquele modelo de dança. Nessa transposição acrescentavam sotaque sentimental ligado à musica portuguesa e malícia rítmica da influência africana. Dessa mistura nasceu o choro, primeiro como forma de frasear e adaptar além da polca, outras danças como a valsa, a habanera, a mazurca e o schottisch. $O$ choro ainda não era um gênero musical, $e$ sim uma forma diferente de tocar as danças da moda (CAZES, 2005, p. 16).

Por meio das revistas, a música europeia passou a ser "absorvida" por todas as classes sociais e mesmo aqueles que não sabiam ler partituras ou não possuíam/tocavam piano, apropriavam-se de alguma forma dessas composições.

\section{Considerações finais}

A imprensa, em geral, e A Revista da Semana, que nos interessa mais de perto, por sua frequência, baixo custo e grande circulação, podem ser consideradas como agentes mediadoras de informações e ideais de educação, pois articulavam grupos de diferentes estratos sociais e interesses, criando uma comunidade de afinidades intelectuais e de sentido.

O Rio de Janeiro era o "espelho do Brasil", já que o que acontecia por lá, mais tarde, se espalhava por todo o país. A cidade capital era a porta de entrada para todas as novidades, inclusive das tendências musicais. No final do século XIX e no princípio do século $\mathrm{XX}$, eram as danças europeias que ditavam o ritmo da música no Brasil. Valsas, polcas, schottisches, maxixes, entre outros, eram os estilos preferidos da população. Nos bailes de família, nos teatros, nos bares, nas ruas, enfim, em qualquer lugar, era a música importada que fazia os brasileiros dançar.

Foram esses, também, os ritmos que passaram a fazer parte das páginas das revistas ilustradas no início do século, quando os periódicos começaram a publicar, semanalmente, partituras para que seus leitores tivessem acesso à música do momento. E essas músicas circularam, chegaram ao interior de Minas Gerais, onde familiares de DATL as extraíram do seu suporte original e organizaram em cadernos para os saraus domésticos ou para complementar os estudos de piano.

$\mathrm{O}$ rádio ainda não existia no Brasil nas primeiras décadas do século $\mathrm{XX}$ e os discos que começavam a surgir no mercado tinham um preço muito alto. Então, a prática de tocar era muito comum já que, além de ser a mais barata, por muitos anos foi a única forma de se ter música nos diversos espaços de sociabilidade. Era comum que na casa dos mais abastados tivesse um piano e, por isso, a publicação de partituras para este instrumento tinha uma certa garantia de recepção. Nesse período, o Rio de Janeiro tinha tantos exemplares que passou a ser chamada de "cidade dos pianos" e, mesmo aqueles que não o possuíam, transpunham as composições para outros instrumentos como flauta, cavaquinho e violão. $\mathrm{O}$ que não podia era ficar sem música!

Este texto busca mostrar, tanto no campo da história da educação como no campo da história da música, que o aprendizado da leitura musical e a educação musical podem acontecer nos "lugares" de mediação do conhecimento, e não somente em espaços escolares (conservatórios, escolas de música e colégios), por meio do uso de estratégias textuais musicais facilitadoras da leitura e, indiretamente, didáticas. 
Notas

1 A realização desta pesquisa contou com o apoio da FAPEMIG.

2 O Jornal do Brasil foi fundado em 1891 e marcou seu lugar na história dos grandes jornais como um precursor de inovações, como o uso de agências de notícias e o envio de correspondentes ao exterior. Teve como colaboradores nomes importantes como Rui Barbosa, Joaquim Nabuco, Manuel Bandeira, Carlos Drummond de Andrade, Carlos Castelo Branco, Otto Lara, entre outros. Após sucessivas crises nas últimas duas décadas o JB deixou de circular na versão impressa no dia 30/08/2010, passando a partir daí a ser publicado apenas na versão digital, via internet.

3 Informação retirada do livro "Panorama da Música Popular Brasileira na Belle Époque" de Ary Vasconcelos. O autor afirma que os primeiros anos do século XX foram de preços baixos e cita alguns exemplos para ilustrar: carne de vaca a 900 réis o quilo; carne de carneiro $2 \$ 000$ (dois contos de réis); de porco $1 \$ 300$ e o café Java a $1 \$ 400$.

4 Lembrando que o acesso ao conteúdo da revista poderia ser feito pelo "ouvir ler" ou pela leitura coletiva.

5 Encarte infantil publicado a partir de 1906 pela Revista da Semana.

6 Nome dado aos grupos de choro no início do século XX.

\section{Referências}

ALVES, Paulo Henrique Pinto Coelho Rodrigues. Partituras em revista:A Revista da Semana como suporte de circulação da música no Brasil na primeira década do século $\mathbf{X X}$. Betim-MG: Universidade Vale do Rio Verde de Três Corações, 2011. Dissertação de Mestrado.

BASTOS, Maria Helena Camara. Espelho de papel. A imprensa e a história da educação. In: ARAÚJO, José Carlos Souza \& GATTI JÚNIOR, Décio (Orgs.) Novos temas em história da educação brasileira: instituições escolares e educação na imprensa. Campinas: Autores Associados; EDUFU, 2002. 225p.

CARLOS, Denise M. \& VEIGA, Cynthia G. A produção da opinião pública sobre a educação escolar em Minas Gerais: um estudo do periódico
"Correio Official de Minas" (década de 50 do século XIX). Anais do III CONGRESSO DE PESQUISA E ENSINO EM HISTÓRIA DA EDUCAÇÃO EM MINAS GERAIS. São João del-Rei, 2005. p.1-15.

CARNEIRO, Giane Araújo Pimentel. As práticas educativas familiares no processo de distinção geracional criança/adulto (Caetité-BA, 19101930). Belo Horizonte: Universidade Federal de Minas Gerais/Faculdade de Educação, 2011. Dissertação de Mestrado.

CASTRO, Maria Teresa Mendes de. A formação da vida musical de Belo Horizonte: sua organização social em torno do ensino de piano. Belo Horizonte: Universidade Federal de Minas Gerais/Faculdade de Educação, 2012. Tese de Doutorado.

CAZES, Henrique. Raízes Musicais do Brasil. Rio de Janeiro: Sesc Rio, 2005.

CHAMON, Carla Simone. Festas no Império. Pedagogia Cívica em Minas Gerais. In: Educação em Revista (UFMG), Belo Horizonte, n.30, p. 93106, 1999.

FONSECA, Thais N. De L. E. "Segundo a qualidade de suas pessoas e fazenda" - Estratégias educativas na sociedade mineira colonial. In: Varia Historia. Vol. 22, n. 35, p. 175-188, jan/jun 2006.

FRYDMAN, Cláudio. A música do leitor: partituras publicadas em revistas cariocas (19001920). Rio de Janeiro: Projeto Músicos do Brasil Uma Enciclopédia, 2008. 10 p. Disponível em: $<$ http://ensaios.musicodobrasil.com.br/claudiofrydman-a-musica-do-leitor.htm. Acesso em: 10 jan. 2010.

GALVÃO, Ana Maria de Oliveira et al. História da Cultura Escrita: séculos XIX e XX. Belo Horizonte: Autêntica Editora, 2007.

GALVÃO, Ana Maria de O. ; JINZENJI, M. Y. ; QUEIROZ, K. A. S. . Mulheres de meios populares e a construção de modos de participação nas culturas do escrito (Minas Gerais, Brasil, século $\mathrm{XX}$ ). Archivos Analíticos de Políticas Educativas / Education Policy Analysis Archives, v. 21, p. 121, 2013. 
GORGULHO, Talitha Maria Brandão. "Aos órfãos que ficaram": estratégias e práticas educativas dos órfãos de familias abastadas na Comarca do Rio das Velhas (1750-1800). Belo Horizonte: Universidade Federal de Minas Gerais/Faculdade de Educação, 2011. Dissertação de Mestrado.

JINZENJI, Mônica Y. ; GALVÃO, A. M. O. ; ALVES, S. . Memórias sobre a infância no meio rural: a escola e outros espaços de sociabilidade (Minas Gerais Brasil, 1920-1950). Revista Portuguesa de Educação, v. 25, p. 9-33, 2012.

JINZENJI, Mônica Y. Cultura impressa e educação da mulher no século XIX. Belo Horizonte: Editora da UFMG, 2010.

JULIO, Kelly Lislie. Práticas educativas e sociabilidades: mulheres forras em São João del Rei e São José del Rei (1808-1840). Belo Horizonte: Universidade Federal de Minas Gerais/Faculdade de Educação, 2007. Dissertação de Mestrado.

LEME, Mônica Neves. E "saíram à luz" as novas coleções de polcas, modinhas, lundus, etc. Música Popular e impressão musical no Rio de Janeiro (1820-1920). Rio de Janeiro: Universidade Federal Fluminense/História, 2006. Tese de Doutorado.

LEME, Mônica Neves. Mercado editorial e música impressa no Rio de Janeiro (séc. XIX) - modinhas e lundus para "iaiás" e "trovadores de esquinas". Anais do I SEMINÁRIO BRASILEIRO SOBRE LIVRO E HISTÓRIA EDITORIAL. Rio de Janeiro, 2004.

LOPES, Eliane Marta Teixeira. Colonizadorcolonizado: uma relação educativa no movimento da história. Belo Horizonte, UFMG, 1985.

LUSTOSA, Isabel. O nascimento da imprensa brasileira. Rio de Janeiro: Jorge Zahar, 2003.

MACEDO, Laura. Música para Professores. Partituras, Primeiras Embalagens. Rio de Janeiro. 2009. Portal Luis Nassif. Disponível em: http://blogln.ning.com/profiles/blogs/partiturasprimeiras. Acesso em: 15 mar. 2010.
MAGALDI, Cristina. Chiquinha Gonzaga e a Música popular do Rio de Janeiro no final do século XIX. Artigo disponível em http://www.livrosgratis.com.br /arquivos_ livros / mre000117.pdf. Acesso em : 15/03/2010.

MAGNANI, Sérgio. Expressão e Comunicação na Linguagem da Música. 2. ed. Belo Horizonte: Editora UFMG, 1996.

OLIVEIRA, Cláudia de; VEllosO, Mônica Pimenta; LINS, Vera. O Moderno em Revistas: Representações do Rio de Janeiro de 1890 a 1930. Rio de Janeiro: Editora Garamond, 2010.

OLIVEIRA, Flávio Couto e S. de. O canto civilizador: música como disciplina escolar nos ensinos primário e normal de Minas Gerais, durante as primeiras décadas do século $\mathrm{XX}$. Belo Horizonte:UFMG/ Faculdade de Educação, 2004. Tese de Doutorado.

PALLARES-BURKE, Maria Lúcia Garcia. A imprensa periódica como uma empresa educativa no século XIX. São Paulo: Faculdade de Educação USP. 1998. Artigo disponível em http://www.fcc.org.br/pesquisa/publicacoes/cp/arqui vos/168.pdf. Acesso em 03/08/2009.

REMEDIOS, Maria José. O jornal Novidades: sentido (s) do educar. Revista Brasileira de História da Educação, Campinas: Autores Associados, n. 6, julho/dezembro 2003.p. 9-27.

REIS, Joseni Pereira Meira. Instâncias formativas, modos e condições de participação nas culturas do escrito: o caso de João Gumes (Caetité-BA, 1897-1928). Belo Horizonte:UFMG/ Faculdade de Educação, 2010. Dissertação de Mestrado.

REIS, Sandra Loureiro de Freitas. Musicologia e Filosofia: mímesis na linguagem musical. In: Anais do XIII ENCONTRO NACIONAL DA ANPPOM, vol. II. Belo Horizonte: ANPPOM, 2001.

REZENDE, Gabriel S. S. Lima. Música, experiência e memória: algumas considerações sobre o desenvolvimento da partitura a partir das obras de Max Weber e Walter Benjamin. In: Revista Espaço Acadêmico, n. 85, 2008. 
SÁ, Carolina Mafra de; GALVÃO, Ana Maria de Oliveira. O teatro como estratégia educativa no Segundo Império: características de uma dramartugia idealizada pelo Conservatório Dramático Brasileiro. In: Thaís Nívia de Lima e Fonseca; Cynthia Greive Veiga. (Org.). História da educação: temas e problemas. Bleo Horizonte: Mazza Edições; FAPEMIG, 2011, v. , p. 295-330.

SILVA, Gisele Taboada da et al. A Revista da Semana em Perspectiva. 2004. 14 p. Artigo disponível em http://www.cantareira.br/thesis2/v2n2/gabriela.pdf. Acesso em 27/04/2010.
SILVA, Solange Maria da. Estratégias e práticas educativas dos negros na Comarca do Rio das Velhas, século XVIII. Belo Horizonte: UFMG/ Faculdade de Educação, 2011. Dissertação de Mestrado.

TABORDA, Márcia Ermelindo. Violão e Identidade Nacional: Rio de Janeiro 1830/1930. 2004. Rio de Janeiro/História: UFRJ, 2004. Tese de Doutorado.

VASCONCELOS, Ary. Panorama da Música Popular Brasileira na Belle Époque. Rio de Janeiro: Livraria Sant'Anna, 1977.

\section{Sobre os autores:}

Mônica Yumi Jinzenji: Possui graduação em Psicologia pela Universidade Federal de Minas Gerais (1999), mestrado (2002) e doutorado (2008) em Educação pela mesma universidade, é Professora do Programa de PósGraduação em Educação, Faculdade de Educação - UFMG, Belo Horizonte.

Eliane Marta S. Teixeira Lopes: Possui graduação em Pedagogia pela Universidade Federal de Minas Gerais (1969), mestrado em Educação pela Universidade Federal de Minas Gerais (1980) e doutorado em Filosofia da Educação pela Pontifícia Universidade Católica de São Paulo (1984). É professora Emérita Faculdade de Educação, UFMG.

Paulo Henrique P. C. R. Alves: Possui graduação em Música (Licenciatura) pela Universidade Federal de Ouro Preto (2007) e Mestrado em Educação pela Universidade Vale do Rio Verde de Três Corações UNINCOR (2011). Atualmente é professor efetivo de Música do Centro Pedagógico da Universidade Federal de Minas Gerais - UFMG.

Recebido em: 23/06/2014

Aprovado em: 11/12/2014 